\title{
Student Bullying of Teachers in California Public Schools
}

\author{
Jia Jian Tin* \\ California School of Professional Psychology - Fresno, Alliant International University, 5130 E Clinton \\ Way, Fresno CA 93727 \\ * E-mail of the corresponding author: jtin@alliant.edu
}

\begin{abstract}
Student Bullying of Teacher (SBT) has gotten increased attention in research but has yet to be recognized by the public or politicians. The American Psychological Association (APA) put together a task force to study and bring awareness to SBT more than a decade ago found nearly $80 \%$ of teachers experience bullying. The current study aims to document the prevalence of SBT in the state of California a decade after the APA study. The present study used an SBT survey, a self-constructed survey based on previous studies. The SBT survey asked participants about their experience of SBT and how they reacted to being bullied. A total of 268 public school teachers in California participated in the study. The study found $85.1 \%(n=228)$ of the teachers experienced in-person bullying and $38.4 \%(n=103)$ experienced eletrocic forms of the bullying. Teachers reported reduced expectations and student engagement due to SBT. Majority of the teachers believed schools, school districts, and parents were not supportive of teachers when addressing the topic of SBT.
\end{abstract}

Keywords: bullying, California, teachers, school intervention

DOI: $10.7176 / \mathrm{JEP} / 11-24-17$

Publication date:August $31^{\text {st }} 2020$

\section{Introduction}

There is a wealth of research on work-place bullying and its impact on victims (e.g, Arseneault, 2017; Espelage, Low, Van Ryzin, \& Polanin, 2015; McVie, 2014). This research is largely restricted to extensive investigations on workplace bullying and its significance. This form of bullying is often carried out by a person with organization power (i.e., supervisor, employer) or someone with equal organization power (i.e., peers) but gain power through sociocultural factors (i.e., male privilege). The negative effects of this kind of harassment include work absences, often in the form of sickness related absence (Hodgins, MacCurtain, \& Mannix-McNamara, 2014), reduced work engagement (Einarsen, Skogstaf, Rorvik, Lande \& Nielsen, 2018), and even suicidal ideation in more extreme situations (Leach, Poyser, \& Butterworth, 2016). In contrast, another type of workplace bullying is not heavily researched - the bullying of individuals traditionally perceived as having positions of power by those in lower positions.

One such instance of this phenomenon is when students bully their teachers, also known as student bullying of teacher or by its acronym, SBT. While the issue has been largely neglected in the past, there has been an increase in awareness of and research in this area in recent years (De Wet, 2010; Garrett, 2014; May \& Tenzek, 2017; Santos \& Tin, 2018). However, majority of the studies were qualitative. While qualitative data have provided a solid foundation for current and future research, few quantitative studies have provided quantitative documentation of the psychological impact of SBT. Qualitative data also do not provide for a good way to compare prevalence rate or other elements of SBT. Quantitative data can help researchers better estimate the occurrence of SBT on a larger scale and improve our understanding of the phenomenon.

\section{Student Bullying of Teachers (SBT)}

While research on SBT has gained significant academic attention as of late, the phenomenon has yet to be recognized by the public or politicians as a pressing matter (Garrett, 2014). Regardless of the stakes, educators play an important role in any society and their work fostering the development of others contributes both directly and indirectly to solving all the complicated global problems (Glaser, 1984). Educators ensure the younger generations are trained and equipped with the necessary skills, character, and knowledge to tackle the world's problems, as such ignoring the realities and impact of SBT will only hinder growth and progress in communities around the world. SBT needs to be considered more carefully, as it has consequences affecting individuals at multiple levels, and the effects are not confined in the classroom or the individual school systems involved. The public and political sector need to be aware SBT is a problem affecting everyone, albeit sometimes indirectly, and 
so the responsibility to solve this problem belongs to everyone (Espelage, Anderman at al., 2013).

One factor hindering the development of research in this field is a lack of awareness of the problem itself within the community and global political debate (Chen \& Astor, 2009). This lack of awareness means SBT cases are handled at an individual level as schools or in some cases teachers are left to come up with their own methods of handling SBT cases. For example, in Santo and Tin's study (2018), most teachers who reported a lack of support from the Ministry of Education in Malaysia also reported a lack of support from higher level administration within their own schools. This lack of support likely causes a feeling of isolation and those teachers become more likely to blame themselves for the bullying (De Wet, 2010).

Terry (1998) suggested the main reason the occurrence of SBT has not caught much public attention is due to the "overly subjective and restrictive views about the nature of bullying." (p. 256). Over the years, academics have come to agree the term bullying has to include the following three key factors - repetition of the action (HarelFisch et al., 2011; Olweus, 1993); an intention to harm (Olweus, 1991, 1993; O’Connell, Pepler, \& Craig, 2000), and the imbalance in power in the relationship (Einarsen, 2000). Therefore, when discussion SBT, this paper refers to repetitive acts by students with a perceived intention to harm teachers and the teachers perceive the student to hold the power in the relationship.

\subsection{Naming the Phenomenon}

Before moving on, it is important to highlight the list of different terms used to describe SBT in past research. Choosing the right terminology is a crucial step to furthering research in the field and allowing the discourse to progress. Currently, databases are flooded with a myriad of different terms used when researching and discussing the SBT phenomenon. This lack of precision in terms could slow down the progress in this area due to the inability to find contemporary studies. SBT is an issue with interested professionals in different disciplines (i.e., mental health, education, politics). Thus, uniformity in terms used to identify the issue is important for effective communication between disciplines. SBT requires input from professionals from several different fields to tackle, so a universal nomenclature is important to ensure the concept is properly communicated across fields of study. To ensure this cross-dialogue can occur, the terminology should be simple and direct.

SBT has been called a list of different terms in past research, including violence against teachers (i.e., Dzuka \& Dalbert, 2007), bullying and harassment of teachers (Benefield, 2004), contrapower bullying (i.e., Benson, 1984), teacher-targeted bullying (Pervin \& Turner, 1998), educator-targeted bullying (i.e., De Wet 2010), and student bullying of teachers (Garrett, 2014). While each of these terms capture a different aspect of the phenomenon. For example, violence highlights how severe SBT can be by highlight physical acts but may imply non-physical acts are less important.

Other terms address the act and the intended target of the act but fails to highlight the perpetrator. This is a problem because administrators and parents also bully teachers (Espelage, Anderman, et al., 2013). In addition, removing the perpetrators from a terminology could unintentional linguistic implications allowing the perpetrator to stay free from the issue (Katz, 2012). Katz (2012) argued phrases such as "the sexual harassment of women" or "the systematic discrimination of African Americans" have the same problem. The perpetrators in these statements have been removed, leaving only the phenomenon and the victim rather than the cause of the situation. Katz argued this is a linguistic move employed to allow the oppressor to stay free from the issue of oppression and remove his status as the responsible party in those circumstances. Those individuals who object to Katz's argument often point out it is not always men who harass women; therefore saying "the sexual harassment of women by men" would be wrong, as the statement excludes women are also perpetrators of these behaviors as well.

Unlike the other phrases, student bullying of teacher acknowledges the perpetrator of the act: students. This phrase is simple, easily understood, and directly confronts the central issue of the situation, while not avoiding blame, or at least properly identifying the perpetrator. Therefore, SBT should be considered as the best term to refer to the phenomenon.

\subsection{Socio-ecology Theory and the Imbalance in Power}

Now that SBT has been established as the preferred phrase, the paper moves on to attempt to explain how the imbalance in power may occur in the teacher-student relationship. SBT and its prevalence have been researched in multiple different countries. For example, in the United States, a study in 2014 found $80 \%$ of teachers reported being victimized and of those, 94\% reported experiencing SBT (McMahon, Martinez et al., 2014). Earlier studies in the United Kingdom (UK) by Terry (1998) and Pervin and Turner (1998) found prevalence rates of 56.4\% 
(Manchester) and 91\% (London) respectively. In South Africa, De Wet and Jacobs (2006) reported 76.7\% of teachers endorsed experiencing SBT. Other countries reported a similar rate of prevalence, including a study in Canada (80\%; Wilson et al., 2011) and a study in Slovakia (85.4\%; Emmerová, \& Kohútová, n.d.). Interestingly a study in Malaysia (Santos \& Tin, 2018) reported a lower prevalence (65.2\%), with another study in Slovakia reporting the lowest rates (49\%: Dzuka \& Dalbert, 2007). One may wonder what causes this discrepancy in prevalence rate, even within the same country.

It is likely the factor of imbalance in power plays an important role in the difference in prevalence of SBT. As Smith and Thompson (2017) pointed out, the bully must be stronger than the bullied or at least perceived to be stronger. So, it becomes improbable for a teacher to be bullied by a student because of the authority granted to the teacher by the institution, unless some other factor causes this imbalance. For example, an inexperienced teacher may inadvertently present himself or herself as weak because of poor classroom management or anxiety; this perceived weakness will influence the perceived authority of the educator. Yet, May and Tenzek (2017) found no pattern when examining educators who were bullied by students. Their studysuggest students did not discriminate or demonstrate any pattern when targeting professors for bullying. While teachers with some experience appeared to be coping better, they did not experience less bullying. Such findings suggest the imbalance in power is not solely created by the teachers' inability to manage their classroom or handle problematic students. Instead, it is more likely the occurrence of SBT is fueled by other factors in addition to the educator's control over the classroom.

The study then turns to socio-ecological theory to attempt to explain the imbalance in power within the teacherstudent relationship. The power given to a teacher by the school or the state is assumed to be inherently social, the respect and high regards of teachers exist because the community values their profession and contribution to the betterment of society (Terry 1998). If the community as a whole respects and values educations and educators, the children who attend school are more likely to respect their teachers too.

The power of community values could explain why one study in Asia reported significantly lower SBT rates than most of the other studies (Santos \& Tin, 2018). Asian cultures are renown for the great amount of respect they place on teachers (Gordon, 1997; Huang \& Asghar, 2018; Lee \& Manning, 2001; Tao, Oliver, \& Venville 2013). Any individual or local group factors might challenge the authority of the teacher has to overpower a strong tradition within the culture. This indicate, respect and value for educators and education could serve as a protective factor against SBT.

However, thought socio-ecological model one can see the authority of a teachers is granted to a wide complex network of macro and micro systems. Local culture could play a significant role in predicting SBT prevalence rate. It could explain why studies from different school districts, cities, or states within the same country may report significantly different prevalence of SBT. For example, Terry (1998) conducted a study in Manchester, UK and found a prevalence rate of 56.4\% while Pervin and Turner (1998) found a rate of $91 \%$ in London. The local climate around the value of academic education is similarly influenced by a multitude of factors.

As discussed earlier, social norms grant teachers their power. This power can also be stripped when other social factors give the student more power than the educator. These factors can be split into two categories: (a.) values contradicting the value of education, reducing the value of the educator and (b.) social norms devaluing the educator as a person. First consider the norms decreasing the value of education. This decrease in the value of education is likely to influence one's perception of teachers as well. So, the power granted to teachers would have decreased among students who value education less or students coming from families and peer groups who value education less. The decrease in the importance placed on fact finding and research, emergences of alternative facts, and history of anti-intellectualism within the United States are also possible contributing factors (Branford et al, 2019).

Another factor challenging the value of education is the commercialization of education as it creates students and school administrations who are more customer minded. For example, studies have found educators reported a level of distrust toward school administration because of lack of support (May \& Tenzek, 2017; Smith \& Brain, 2000). Administration was seen as siding with students instead of the teachers because it was more important to keep the customers satisfied. This change in allegiance transforms the teacher-student relationship into a costumer-server relationship (Cain, Romanelli, \& Smith, 2012). All these factors contribute to the devaluing of the occupation of educators, allowing the student to cross the teacher-student relationship boundary and bully the teachers.

The second group of factors devalue the educator as a person, rather than devalue education per se. For example, students and teachers may have difference in ideologies on important topics. Students may regard their own personal views as true and dispute any contrary views from a teacher. May and Tenzek (2017) found a major trigger for bullying events was diversity topics or politically charged topics like abortion. The student can now justify 
their disrespectful behavior towards the teacher (e.g., a teacher who is for abortion may be labelled as a supporter of murderers). So, the student has devalued the teacher ideologies and has impunity to disregard the teacher's authority as an educator. May and Tenzek pointed out student's mindset can be influenced by a multitude of other sources, including their family and relatives, the internet, medias, and so on.

Another factor affecting the student's evaluation of their teacher as a person is implicit bias. This bias can be based on the teacher's gender, sexual orientation, ethnicity and race, physical size, visible disabilities and so on. Like political values discussed earlier, these values are also picked up from similar sources. For example, children were more likely to have gender discriminatory attitude if their parents held the same views (Dhar, Jain, \& Jayachandran, 2019). Implicit bias functions by reducing the perceived value of the educator as a person. For example, a more outspoken student may attempt to intimate a timid teacher. May and Tenzek (2017) found students would sexualize and dehumanize female teachers to reduce their authority in the classroom. Another example would be a student insulting a teacher's race or sexual orientation. Other studies found students would target male teachers' homosexuality in an attempt to reduce the teachers' superior position of masculinity (Lahelma, Palmu, \& Gordon 2000; Mooij, 2011).

This formulation is an attempt to explain how SBT can occur. While previous studies have looked at models of traditional bullying (e.g., Santos \& Tin, 2018), these models do not address what causes the flip in authority in the teacher-student relationship. One study suggested the social-ecological theory as an explanation for SBT (Espelage et al., 2013). Social-ecological theory argues individual attitudes and behaviors are influenced by factors like their family, peers, school, work, and other social environmental factors.

The current study proposed the key predictor of prevalence of SBT would the decrease in value of education and the devaluation of the teacher as a person as potential ways the student gain authority, a macrosystem in the framework. Nonetheless, this is an aspect of SBT the community lacks information. So before proceeding further, one should consider what researchers in the field know and do not know about SBT at this moment.

\subsection{What We Know about SBT}

Next, we move on to discuss the consistencies and inconsistencies of SBT. When it comes to the bullies, the few SBT studies seem to agree it was difficult to identify specific demographic groups. For example, studies indicated male and female students carry out SBT at relatively same rates (Pervin \& Turner, 1998; May and Tenzek, 2017). Studies on primary and secondary school students identify the early teens (age 13-14) were most likely to carrying out bullying (Pervin \& Turner, 1998; Terry, 1998; Özkiliç, 2012). Unfortunately, many researchers fail to include demographic information about student bullies (e.g., Santos \& Tin 2018). This creates a hole in the understanding of SBT as it was hard to determine if certain students were more at risk to carrying SBT.

In contrast, research on the characteristics of teachers who are targeted seem to contradict each other. For example, Özkiliç (2012) found no gender differences in male or female teachers who were targeted for SBT. However, another study found male teachers were more likely to be targeted for SBT (McMahon, Martinez, et al., 2014). Another factor often studied is whether years of experience as a teacher affects the rate of SBT experienced (Emmerová \& Kohútová, n.d.; May \& Tenzek, 2017; Santos \& Tin, 2018). Some studies indicated teachers with shorter teaching experience were targeted more often (Emmerová \& Kohútová, n.d.; Santos \& Tin, 2018); others show no pattern when it comes to teaching experience (May \& Tenzek, 2017). Overall, the inconsistencies in the findings make it difficult to identify any outstanding characteristics of bullied teachers.

Some research in SBT is very consistent, however. For example, there is consensus regarding the locations where SBT occurs. Results from past studies found SBT occur both in the classroom, in other areas of the school compound, in public areas outside of schools, and even at the teachers' home (Pervin \& Turner, 1998; Terry 1998; Lahelma et al, 2000; De Wet, 2010). The prevalence of the type of bullying has been very consistent across research as well. Most research found less severe forms of bullying to be more frequent (i.e., verbal abuse, ignoring) and more severe forms of bullying to occur less often (i.e., physical assault, damaging of property; Emmerová \& Kohútová, n.d.; McMahon, Martinez, et al., 2014; Özkiliç 2012; Santos \& Tin, 2018).

Beyond consistencies and inconsistencies, other studies have attempted to highlight prevalence of different forms of bullying often ignored in SBT studies such as cyberbullying (Bester, Du Plessis, \& Treurnich, 2017; Minor, Smith 2007) and sexual harassment (James, et al., 2008, Lahelma et al., 2000; May \& Tenzek, 2017; Mooij, 2011; Robinson, 2000). In this age and time, cyberbullying is a major player in the realm of bullying especially considering the increase in usage of electronic devises in the classroom and, of course, the sudden surge in distance learning due to the COVID-19 pandemic. Sexual harassment, on the other hand, is a problem ignored for 
generations as it is a topic most feel uncomfortable discussing even under normal circumstance (i.e. peer-to-peer bullying).

Qualitative research has been able to collect rich data on the teacher's experience of and reactions to SBT (e.g., De Wet, 2010). For example, teachers experiencing SBT reported a variety of somatic complains, such as sleep disturbance, night terrors, unwanted weight loss, nausea when approaching school, headaches and so on (De Wet, 2010; Fahie \& Devine, 2014; Santos \& Tin, 2016). Studies have also found links between experience of SBT and negative psychological effects like stress, reduced work engagement, burnout, hypervigilance, feeling of failure or inadequacy, social isolation or withdrawal, and even thoughts of suicide (Chen \& Astor, 2009; De Wet, 2010, Fahie \& Devine, 2014; La Greca \& Harrison, 2005; Lewis, 2004; Santos \& Tin, 2018). Academically, teachers who experienced SBT have reported reducing expectation of student performance, decreasing class engagement, switching school, or even leaving the professional altogether (Astor, Meyer, Benbenishty, Marachi, \& Rosemond, 2005; Chen \& Astor, 2009; De Wet 2010; May \& Tenzek, 2017; Santos \& Tin, 2018). The consequence of SBT is a decrease in quality of education provided to other students not involved in the bullying incident.

\subsection{The Present Study}

While past research have conducted research on a national scale (Espelage, Anderman at al., 2013), none of the currently published studies have collected data on SBT in California. So, the present study aimed to collect descriptive statistics on the phenomenon of SBT within the state of California. As discussed above, the geographical area, political climate, and other locational factors could significantly affect the rate of SBT. The study focused on the state of California to limit the effects of such confounding variables. Some improvements were made to the survey from Santos and Tin, including renaming the phenomenon from educator targeted bullying to SBT, collecting data on ZIP code for the purpose of estimating socioeconomic status and comparison of rural and urban schools, and the addition of sexual harassment and bullying through electronic means.

This study only collected data from public schools and excluded charter and private schools, due to the difficulty of controlling confounding variables. For example, unlike public school, Title IX of the United States Federal Law does not apply to private schools, unless the school receives federal funding (Garner, 2018). Although, in California, private schools receiving state funding must comply with California Education Code $§ 221.5$, which grants similar civil protection to student as does Title IX. Charter school and private school also have the privilege of handpicking students, skewing many key variables potentially affecting rate of SBT (i.e., poverty level, class sizes). All these differences could potentially contribute to burnout of the teachers and thus were all confounding variables to this study. The limitation to California teachers was also an attempt to control for confounding variables as different states have different requirement for teaching and different systems in place to support their teachers. Because the survey is designed to focus on recent experience of SBT, retired teachers were excluded from the study.

The current research hypothesize the sample in California will report a higher frequency of SBT when compared to the sample in Malaysia. As discussed above, geopolitical factors and social norms have a possible role in enabling SBT. These factors must overcome the social value placed on teachers in order to enable SBT, thus, if this is true, then the Asian sample will report a lower rate of SBT, as any factors encouraging SBT must first over come the high social value traditionally placed on teachers. Second, the study hypothesize lower SES would predict a higher rate of SBT as past studies have found a link between lower SES and delinquency (e.g. Beyers, Loeber, Wikstrom, \& Stouthamer-Loeber, 2001).

\section{Methodology}

The data for this analysis was part of a study involving a separate compound conducted by the author. The full study included self-reported burnout of the teachers. In this study, in-depth data on SBT, the prevalence rate, and the teachers' reaction to experience SBT were reported.

\subsection{Participants and Procedure}

A total of 406 participants attempted the online survey. Of those, 11 did not consent to participate in the research study, 83 were screened out of the survey because they were not teachers in a public school in California, and 44 were removed for having incomplete surveys. A total of 268 participants were included in the data analyses.

The proposal for the study was submitted and approved by the Alliant International University Institutional Review 
Board (IRB). The survey was distributed online and in some cases, teachers with publicly accessible emails were contacted via mass emailing. The study documents sent to participants included a cover letter explaining the purpose of the study, assurance of participant's anonymity and confidentiality, and provided contact details of the researcher, and IRB, and a Qualtrics link to the online survey. The cover letter also included the definition of SBT specifically the importance of repetitive nature of the phenomenon.

Once the participants clicked on the Qualtrics link, they were presented with an electronic consent form followed by a brief screening questionnaire to ensure they meet all criteria for the study (i.e., inclusion and exclusion criteria) If they met the study criteria, participants were first asked to complete a demographic questionnaire followed by the SBT survey.

\subsection{Materials}

Santo and Tin's (2018) survey was adapted for the current study. The survey included descriptive and qualitative questions; modifications included language as well as changing Likert-type responses to more interval responses (see below). Descriptive questions were edited from a Malaysia education system to fit the American education system. Sexual harassment was added as a form of SBT and option was added to reported SBT that happened online. Finally, certain questions were reworded to use more inclusive language.

The SBT survey used in this study had a total of 25 questions. The first question asked teachers about their experience of bullying from parents, and teachers rated their experience on a 0 (Never) to a 100 (Every workday) scale. Then, teachers were asked to recall the frequency of different types of SBT they had experienced in the past year. Teachers rated their experience of SBT on the same scale (0 to 100). The types of bullying queried in the survey included verbal abuse/threat, physical abuse/threat, ignoring, spreading rumors, damaging property (not included for electronic bullying), sexual harassment, and other (a open-ended option). After reporting on the prevalence of bullying, teachers were asked questions about their experience of bullying, including questions about the bully or bullies, who were targeted, characters of the bullying, how teachers reacted to experiencing bullying, and finally whether schools, districts, and parents were aware of SBT.

During data analysis, the total student bullying was the sum of total in-person bullying and total online bullying. Total in-person bullying was computed by adding the total prevalence of each type of in-person bullying and divided by six (excluding other). Total online bullying was computed in a similar manner by taking the average of online bullying types. Another datum that was converted was ZIP code. The median income of the ZIP code provided was used to estimate socioeconomic status (SES). Data for median income was obtained from Point2Home, which uses data from the American Community Survey 2018.

\section{Results}

Of the 268 teachers, majority of the participants were female $(91 \%, n=244), 8 \%(n=22)$ were male and two participants indicated they preferred to self-identify but did not. Table 1 below shows cross-tabulation of demographic data. 
Table 1. Cross-tabulation of demographic variables

\begin{tabular}{|c|c|c|c|c|c|c|c|c|c|c|c|}
\hline \multirow[t]{2}{*}{ Age range } & \multirow[t]{2}{*}{ n (\%) } & \multicolumn{2}{|c|}{$\begin{array}{c}\text { In-person } \\
\text { bullying }\end{array}$} & \multicolumn{2}{|c|}{$\begin{array}{c}\text { Online } \\
\text { bullying }\end{array}$} & \multicolumn{3}{|c|}{ Years of Teaching } & \multicolumn{3}{|c|}{ Years at current school } \\
\hline & & $\mathbf{n}$ & $\%$ & $\mathbf{n}$ & $\%$ & Years & $\mathbf{n}$ & $\%$ & Years & $\mathbf{n}$ & $\%$ \\
\hline \multicolumn{12}{|l|}{$21-30$} \\
\hline Male & $5(1.9 \%)$ & 4 & 80.0 & 3 & 60.0 & $\begin{array}{l}1-5 \\
6-10\end{array}$ & $\begin{array}{l}4 \\
1\end{array}$ & $\begin{array}{l}80.0 \\
20.0\end{array}$ & $\begin{array}{l}1-5 \\
6-10\end{array}$ & $\begin{array}{l}5 \\
0\end{array}$ & $\begin{array}{c}100.0 \\
0.0\end{array}$ \\
\hline \multirow[t]{2}{*}{ Female } & $\begin{array}{c}51 \\
(19.0 \%)\end{array}$ & 48 & 94.1 & 21 & 41.2 & $1-5$ & 36 & 70.6 & $1-5$ & 48 & 94.1 \\
\hline & & & & & & $\begin{array}{l}6-10 \\
>20\end{array}$ & $\begin{array}{c}14 \\
1\end{array}$ & $\begin{array}{c}27.5 \\
2.0\end{array}$ & $\begin{array}{l}6-10 \\
>20\end{array}$ & $\begin{array}{l}3 \\
0\end{array}$ & $\begin{array}{l}5.9 \\
0.0\end{array}$ \\
\hline \multicolumn{12}{|l|}{$31-40$} \\
\hline \multirow[t]{2}{*}{ Male } & $10(3.7 \%)$ & 4 & 40.0 & 2 & 20.0 & $1-5$ & 2 & 20.0 & $1-5$ & 4 & 40.0 \\
\hline & & & & & & $\begin{array}{c}6-10 \\
11-15\end{array}$ & $\begin{array}{l}6 \\
2\end{array}$ & $\begin{array}{l}60.0 \\
20.0\end{array}$ & $\begin{array}{c}6-10 \\
11-15\end{array}$ & $\begin{array}{l}6 \\
0\end{array}$ & $\begin{array}{c}60.0 \\
0.0\end{array}$ \\
\hline \multirow[t]{4}{*}{ Female } & $\begin{array}{c}72 \\
(26.9 \%)\end{array}$ & 60 & 83.3 & 22 & 30.6 & $1-5$ & 18 & 25.0 & $1-5$ & 47 & 0.0 \\
\hline & & & & & & $6-10$ & 26 & 36.1 & $6-10$ & 18 & 25.0 \\
\hline & & & & & & $11-15$ & 21 & 29.2 & $11-15$ & 7 & 9.7 \\
\hline & & & & & & $16-20$ & 7 & 9.7 & $16-20$ & 0 & 0.0 \\
\hline $\begin{array}{l}\text { Self- } \\
\text { identified }\end{array}$ & $1(0.4 \%)$ & 1 & 100.0 & 0 & 0.0 & $6-10$ & 1 & 100.0 & $1-5$ & 1 & 100.0 \\
\hline \multicolumn{12}{|l|}{$41-50$} \\
\hline \multirow[t]{3}{*}{ Male } & $4(1.5 \%)$ & 4 & 100.0 & 2 & 50 & $1-5$ & 0 & 0.0 & $1-5$ & 1 & 25.0 \\
\hline & & & & & & $11-15$ & 0 & 0.0 & $11-15$ & 1 & 25.0 \\
\hline & & & & & & $\begin{array}{c}16-20 \\
>20\end{array}$ & $\begin{array}{l}2 \\
2\end{array}$ & $\begin{array}{l}50.0 \\
50.0\end{array}$ & $\begin{array}{c}16-20 \\
>20\end{array}$ & $\begin{array}{l}2 \\
0\end{array}$ & $\begin{array}{c}50.0 \\
0.0\end{array}$ \\
\hline \multirow[t]{4}{*}{ Female } & $\begin{array}{c}76 \\
(28.4 \%)\end{array}$ & 65 & 85.5 & 29 & 38.2 & $1-5$ & 4 & 5.3 & $1-5$ & 29 & 38.2 \\
\hline & & & & & & $6-10$ & 10 & 13.2 & $6-10$ & 14 & 18.4 \\
\hline & & & & & & $11-15$ & 10 & 13.2 & $11-15$ & 11 & 14.5 \\
\hline & & & & & & $\begin{array}{c}16-20 \\
>20\end{array}$ & $\begin{array}{l}23 \\
29\end{array}$ & $\begin{array}{l}30.3 \\
38.2\end{array}$ & $\begin{array}{c}16-20 \\
>20\end{array}$ & $\begin{array}{c}14 \\
8\end{array}$ & $\begin{array}{l}18.4 \\
10.5\end{array}$ \\
\hline \multicolumn{12}{|l|}{$51-60$} \\
\hline \multirow[t]{3}{*}{ Male } & $3(1.1 \%)$ & 3 & 100.0 & 2 & 66.7 & $1-5$ & 1 & 33.3 & $1-5$ & 1 & 33.3 \\
\hline & & & & & & $6-10$ & 0 & 0.0 & $6-10$ & 1 & 33.3 \\
\hline & & & & & & $>20$ & 2 & 66.7 & $>20$ & 1 & 33.3 \\
\hline \multirow[t]{4}{*}{ Female } & $\begin{array}{c}41 \\
(15.3 \%)\end{array}$ & 34 & 82.9 & 19 & 46.3 & $1-5$ & 1 & 2.4 & $1-5$ & 7 & 17.1 \\
\hline & & & & & & $11-15$ & 3 & 7.3 & $11-15$ & 5 & 12.2 \\
\hline & & & & & & $16-20$ & 8 & 19.5 & $16-20$ & 7 & 17.1 \\
\hline & & & & & & $>20$ & 29 & 70.7 & $>20$ & 12 & 29.3 \\
\hline $\begin{array}{l}\text { Self- } \\
\text { identified }\end{array}$ & $1(0.4 \%)$ & 1 & 100.0 & 1 & 100.0 & $>20$ & 1 & 100.0 & $>20$ & 1 & 100.0 \\
\hline \multicolumn{12}{|l|}{61 and up } \\
\hline Male & $0(0.0 \%)$ & 0 & 0.0 & 0 & 0.0 & & 0 & 0.0 & & 0 & 0.0 \\
\hline \multirow[t]{4}{*}{ Female } & $4(1.5 \%)$ & 4 & 100.0 & 2 & 50.0 & $1-5$ & 0 & 0.0 & $1-5$ & 2 & 50.0 \\
\hline & & & & & & $6-10$ & 0 & 0.0 & $6-10$ & 1 & 25.0 \\
\hline & & & & & & $16-20$ & 3 & 75.0 & $16-20$ & 1 & 25.0 \\
\hline & & & & & & $>20$ & 1 & 25.0 & $>20$ & 0 & 0.0 \\
\hline
\end{tabular}




\subsection{Levels and Types of SBT}

Prevalence rate for each type of bullying is reported in Table 2. As can be seen, $85.1 \%(n=228)$ of the teachers reported experiencing in-person SBT in the past year. Just over $38.4 \%(n=103)$ reported being subjected to SBT through electronic means (i.e., social media, email etc) and $64.9 \%(n=174)$ reported bullying by parents.

Table 2. Prevalence rate for different types of SBT

\begin{tabular}{lcclcc}
\hline Type of in-person SBT & $\mathbf{\%}$ & $\boldsymbol{n}$ & Type of online SBT & \% & $\boldsymbol{n}$ \\
\hline Verbal abuse & 72.0 & 193 & Verbal Abuse & 20.9 & 56 \\
Physical abuse & 37.7 & 101 & & & 76 \\
Ignoring the teacher & 81.7 & 219 & Ignoring the teacher & 28.4 & 51 \\
Spreading rumors & 41.4 & 111 & Spreading rumors & 19.0 & \\
Damaging property & 53.4 & 143 & & 9.7 & 26 \\
Sexual harassment & 21.3 & 57 & Sexual harassment & 4.9 & 13 \\
Other & 16.0 & 43 & Other & &
\end{tabular}

\subsection{Characteristics of the Bully(ies)}

Characteristics of the students carrying out SBT were reported by 203 teachers. The frequency of each endorsement is shown in Table 3 and 4. For questions in Table 3, participants could only select one option. Table 4 displays a question where participants were allowed to select as many options as they desired.

Table 3. Teachers' report on characteristics of SBT

\begin{tabular}{l} 
Questions and Options \\
\hline Did you know the bully? (In-person)
\end{tabular}

\section{$\%$}

$n$

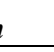

Total

I always know

Most of the time I know

Half the time I know

Most of the time I don't know

I never know

Did you know the bully? (Online)

I always know

Most of the time I know

Half the time I know

Most of the time I don't know

I never know

Was SBT restricted to one gender group?

Boys only

Mostly boys

Equal between boys and girls

Mostly girls

$\begin{array}{cc}44.2 & 107 \\ 38.8 & 94 \\ 8.7 & 21 \\ 3.3 & 8 \\ 5.0 & 12\end{array}$

242

$\begin{array}{cc}45.7 & 102 \\ 19.3 & 43 \\ 10.8 & 24 \\ 3.1 & 7 \\ 21.1 & 47\end{array}$

$19.2 \quad 39$

$35.0 \quad 71$

$35.0 \quad 71$

$10.4 \quad 21$ 
Girls only

Do student(s) carry out SBT alone?

Only alone

Mostly alone

Equal mixture

Mostly in groups

Only in groups

Did SBT occur in the classroom

Only in the classroom

Mostly in the classroom

Equal mixture

Mostly out of classroom

Only out of classroom
$0.4 \quad 1$

$\begin{array}{cc}12.8 & 26 \\ 28.0 & 57 \\ 34.0 & 69 \\ 23.2 & 47 \\ 2.0 & 4\end{array}$

203

$\begin{array}{cc}25.1 & 51 \\ 34.0 & 69 \\ 29.1 & 59 \\ 8.4 & 17 \\ 3.4 & 7\end{array}$

Table 4. Characteristics of the bully

\begin{tabular}{lccc}
\hline Question and options & \% & n & Total \\
\hline What were the characteristics of the student who carried out SBT? & & & 203 \\
Difficulty to say because I don't teach them & 7.9 & 16 & \\
Difficult student(s) for most teachers & 68.0 & 138 \\
Only a few teachers have trouble with the student(s) & 7.9 & 16 \\
Academically underperforming student(s) & 62.1 & 126 \\
Academically overperforming student(s) & 6.4 & 13 \\
"Popular" students & 30.5 & 62 \\
wealthier students & 13.8 & 28 \\
"Loner(s)" & 7.9 & 16 \\
Difficulty to categorize/can't generalize & 9.4 & 19 \\
\hline
\end{tabular}

\subsection{Consequence of Experiencing SBT}

A total of 197 teachers endorsed a wide variety of changes to their teaching styles as a result of experiencing SBT. The most frequently endorsed consequence was a restriction to the range of activities they engaged with students $(66.5 \%, n=131)$. Table 5 shows a breakdown of the teachers' response. 
Table 5. Consequences of experiencing SBT

\begin{tabular}{lccc}
\hline Question and options & \% & n & Total \\
\hline How has experiencing SBT affect your teaching style & & & 197 \\
Make less academic/cognitive demands on students & 19.8 & 39 \\
Have lower expectation of student's behavior & 28.9 & 57 \\
Accept lower levels of co-operations in class & 33.5 & 66 \\
Restrict the range of activities I do with students & 66.5 & 131 \\
Dislike the student who bullied me & 37.1 & 73 \\
Pass the bully so I don't have to deal with them anymore & 9.6 & 19 \\
Fail the bully out of spike & 3.0 & 6 \\
Publicly shame the bully & 5.6 & 11 \\
Stop supporting the bully & 17.8 & 35 \\
I don't change how I teach & 22.3 & 44 \\
\hline
\end{tabular}

\subsection{Teachers' Perception of SBT}

The next portion of the survey addresses teachers' personal perception of certain attributes of SBT. These questions allow a better understanding of the phenomenon of SBT from the perspective of teachers.

\subsubsection{Who experiences SBT?}

The majority of the 196 teachers believed most, if not all, teachers experienced SBT $(76.0 \%, n=149)$. Around $12.8 \%(n=25)$ believed inexperienced teachers were targeted more for bullying

\subsubsection{Who to tell about SBT?}

A breakdown of responses of 190 teachers showed teachers preferred to share their experiences with colleagues $(74.2 \%, n=141)$, followed by family and friends $(61.1 \%, n=116)$, and the principal $(56.3 \%, n=107)$. A small percentage of teacher choose not to share their experience $(8.4 \%, n=16)$ and an even smaller percentage shared their experience with superintendents $(3.2 \%, n=6)$.

\subsubsection{How did sharing the SBT experience felt?}

A large portion of the 197 teachers felt sharing their experiences had no positive effect at all $(43.7 \%, n=86)$. Others felt it was a waste of time $(29.4 \%, n=58)$ or they saw short-term improvements $(23.9 \%, n=47)$. Only $9.7 \%(n=18)$ of the teachers had their problems resolved after sharing their experience of SBT. A small portion of the teachers experienced negative consequences of sharing their experience with SBT. A total of $14.7 \%(n=$ 29) reported feeling ineffectual after sharing their experience, though it was not clear what caused them to feel such a way.

\subsubsection{What stopped you from sharing?}

A total of 197 teachers shared their thoughts with $31.0 \%(n=61)$ endorsing the lack of confidence in the reporting system put in place by the school, $21.8 \%(n=43)$ thought they could handle it themselves, and $16.8 \%(n=33)$ reported there was no mechanism in place for them to report the issue. Other teachers worried reporting would make them look incompetent $(14.7 \%, n=29)$ and $19.3 \%(n=38)$ thought SBT was part of the job.

\subsection{Socioeconomic Status and SBT}

A multivariate regression analysis was conducted to investigate if socioeconomic status (SES) could predict an increase in rate of both in-person and online bullying. The analysis was performed using General Linear Model 
with SES inserted into the fixed factor and total in-person bullying and total of online bullying were inserted as dependent variables. The Box's test of equality of covariance matrices was significant $(p<0.001)$ thus the results from the Pillai's Trace was used. The model found SES does not predict the rate of SBT, $F(2,338)=0.92, \mathrm{p}=$ 758. When observed individually, SES failed to predict both in-person bullying $(p=0.756)$ and online bullying $(p=0.991)$.

Table 6. Awareness of SBT

\begin{tabular}{lccc}
\hline Questions and options & \% & n & Total \\
\hline Do you think your school is aware of SBT? & & 197 \\
Yes, and the school is supporting the teachers & 28.4 & 56 & 109 \\
Yes, but the school is not supporting the teachers & 55.4 & 32 & 16.2 \\
No & & 33 \\
Do you think your school district is aware of SBT? & 16.8 & 110 \\
Yes, and the district is supporting the teachers & 55.8 & 54 \\
Yes, but the district is not supporting the teachers & 27.4 & & \\
No & & 6.1 & 12 \\
Do you think parents are aware of SBT? & 40.1 & 79 \\
Yes, and parents are supportive of the teachers & 53.8 & 106 \\
Yes, but parents are not supportive the teachers & & \\
No
\end{tabular}

\section{Discussion}

One of the main goals of this study was to investigate and document the prevalence rate of student bullying of teachers (SBT) at a more localized level than the national survey conducted by the American Psychological Association (McMahonm, Martinez, et al., 2014). The current study was grounded in a social-ecological theory that predicts the localized value of education and perception of educators will influence the rate of SBT. The study documented the prevalence of different forms of SBT in California and compared these estimates to rates collected in past research.

The current study found a reasonably similar prevalence rate of SBT in California when compared to the national study done by McMahon and colleagues (2014). However, the prevalence of SBT differed when compared to international studies in which some countries, for example, Malaysia (65.2\%; Santos \& Tin, 2018) reported lower rates while some United Kingdom (91.0\%; Pervin \& Turner, 1991) studies reported higher rates. Based on socialecological theory, there were many possible reasons for these differences, such as a difference in cultural values, the prospect of education, political climate, and even the method in which data was collected. However, there were not enough participants for the study to break down California teachers into different geographical areas to study specific trends. The design of the current study also did not collect the data necessary to investigate other factors. In addition, the differences in some of the results could be caused by the way teachers were asked about their SBT experience. For example, Pervin and Turner (1998) asked if teachers ever experienced SBT, other studies (e.g., McMahon, Martinez, et al., 2014) asked about SBT experience within the current or past year, and the current study asked if teachers had experienced SBT in the past year. It is impossible to tell if the wording does cause a difference in the rate. Still, consistency in wording could be an important aspect for future research to enable a more precise comparison of prevalence rate.

The current data on the prevalence of specific types of SBT were more consistent with previous research. Verbal abuse and intentional ignoring of teachers were the most common forms of bullying, as was the case in previous studies. The rates of other forms of SBT were lower, consistent with previous research indicating more severe 
forms of bullying had a lower prevalence rate (Benefield, 2004; De Wet, 2010; De Wet \& Jacobs, 2006; James et al., 2008; Santos \& Tin, 2018).

The consistency regarding the types of bullying reported was also expected. SBT might have been opportunistic and impulsive as indicated by findings on student bullying behaviors (Alvarez-Garcia, et al, 2015). Students are likely to engage in SBT when the opportunity presents itself, for example, walking by a teacher in the hallway and verbally abusing the teacher, talking back at the teacher when addressed in class, or scratching the teacher's car when there was no witness around. However, bullying with low-to-moderate severity was more likely to be tolerated, and teachers were less likely to report the incident (May \& Tenzek, 2017); thus, actions were less likely be to be taken against the student. The lack of consequence could lead to an increase in the repetition of SBT, accounting for the increase in the prevalence rate.

The current study asked if teachers thought any specific category of teachers was targeted more often. The results showed a majority of teachers agreed most, if not all, teachers experience SBT. This finding was consistent with other new studies, which found no consistent differences in the characteristics of teachers who were and who were not bullied (e.g., May and Tenzek, 2017). It was important to avoid scapegoating inexperienced teachers or victimblaming attitudes like claiming teachers are bad at handling problematic behaviors. Such distinction was important as scapegoating and victim-blaming could encourage the development of learned helplessness among victims of bullying, in this case, the teachers experiencing SBT (Pepler \& Craig, 2000). It is worth noting, older studies (e.g., Pervin \& Turn, 1998) found teachers reported inexperienced and newer teachers to be more likely to be targeted for SBT. This shift is possibly a result of teachers confiding between one another about their experience of SBT. As found in the current study, $74.2 \%$ of teachers confide specifically with colleagues. Pervin and Turner (1991) found $41.0 \%$ of teachers confided with friend/colleage. There appeared to be a substantial increase in teachers sharing their SBT experience with one another. Thus, causing an increase in awareness of the phenomenon among teachers.

Perhaps not surprisingly, the present study found SBT had an impact on the teacher-student relationship, with teachers expressing a more negative attitude towards the bully (37.1\%) and, in some cases, was less likely to help the bully in academic work (17.8\%). This change in attitude toward the bully appeared to be an attempt to reduce contact with the bully. Other more drastic methods were endorsed, though at a lower frequency, such as passing the bully to avoiding having them in class again (9.6\%), failing the bully out of spite $(3.0 \%)$, and even publicly shaming the bully (5.6\%). It appeared the primary concern of teachers was to reduce contact hours with the problematic students as the more vengeful options were not highly endorsed.

Unfortunately, a teacher's withdrawal from the bully likely further validated the student's disregard and lack of appreciation for his or her education (De Wet \& Jacob, 2006; May \& Tenzek, 2017; Santos \& Tin, 2018). The teacher's withdrawal will only add to the devaluation of academic success as it becomes harder and harder for the bully to pursue education due to the lack of support. However, it is vital to highlight the actions endorsed by the teachers suggest they had to take matters into their own hands. These actions imply the schools may not have an effective system in place for teachers to handle bullies in a manner not requiring them to isolate the bully. It was crucial for schools to have policies providing viable and effective intervention targeting these students. It was important to highlight nearly half (47.8\%) of the teachers in this study did not report SBT because they had little confidence in mechanism put in place or there was no mechanism in place for them to report. First, the lack of proper intervention programs may signal to teachers the schools were not aware or not supportive of them. Second, the lack of policies addressing SBT can be an indication to the bullies SBT was tolerated in the school and reducing the fear of carrying out SBT (Pepler \& Craig, 2000).

Next we must also consider the students who carry out SBT. The majority of teachers highlighted two specific categories, students with whom most teachers had trouble and academically underperforming students. This result was consistent with past research (Santos \& Tin, 2018). SBT might have been a consequence of students externalizing their frustration with their academic shortcomings. Once again, this point towards a lack of intervention program or support system for students. Acting out is a common externalizing behavior among students who are struggling in school (Thomas, Bierman, Thompson, \& Powers, 2008) due to a multitude of other factors outside of the lack of cognitive ability. From learning disability impacting reading, writing, or arthimetic abilities to highly specific issues with like impairment in verbal reception and expression, when a child does not receive a support they need, externalizing is a common outcoming. In the case of SBT, the teacher becomes the unfortunate recipient of the externalized behavior.

SBT also affected the teachers' attitude towards the bully, thus causing a detrimental effect on the teacher-student relationship. SBT also had a lasting impact on the teachers' attitude towards teaching, suggesting the impact of 
SBT goes beyond the teacher-student relationship. Teachers become less effective and disenfranchised; in some cases, teachers may leave the profession completely if they are sufficiently frustrated. A large percentage of teachers $(66.5 \%)$ reported that they restricted the range of activities they had with students in general after experiencing SBT. Teachers also reported reducing behavioral expectations $(28.9 \%)$, academic expectations $(19.8 \%)$, and increase tolerance of misbehavior in class $(33.5 \%)$.

These results raise concerns over the overall performance of schools, and on the broader scale, the effectiveness of the education system. The results indicate SBT is no longer just an issue between the student(s) carrying out the bullying and the teacher(s). SBT indirectly hindered the learning of other students and thus reduced the overall performance of the school as well.

It is important to note workplace bullying was linked to attrition and turnover rates. Teachers in the United States already have many other factors linked to increase turnover rates like the lack of funding and other political pushback (Podolsky et al., 2016). Teacher attrition was already a documented concern of the US Education system (Dove, 2004). SBT appears to be yet another major problem ignored by policymakers and higher administration in education that could further impact the retention of teachers. Though the study did not query if teachers did ever consider leaving their profession because of SBT.

Because of the current importance of the internet, it was also essential to examine the impact of online bullying. There have been studies investigating the effect of cyberbullying (Bester et al., 2017; Minor et al., 2013; Smith 2007). The current study found online forms of SBT occur at a much lower rate $(38.4 \%)$ when compared to inperson bullying $(85.1 \%)$. This result does not imply the importance and possible impact of online bullying should be ignored, however. Cyberbullying is a growing trend, and the guarantee of anonymity reduces the risk of engaging in these behaviors (Bester et al., 2017; Minor et al., 2013). Cyberbullying can also feel more invasive, where it becomes more difficult to hide and escape from the bully. Thus, more research needs to look into the matter alongside in-person bullying to get a better understanding of how the two interact with the health and wellbeing of teachers.

\subsection{Limitations and Recommendation for Future Studies}

Two crucial limitations for the present study are the sample size and the demographics of the participants. The sample size was small compared to the number of public school teachers in the United States. The current sample caused two key issues; firstly, the study could not break down the sample into smaller groups to investigate if there were differences between school districts or county. It was possible if research could identify specific areas with significantly lower or higher rates of SBT and further study potential factors causing the difference in prevalence. The second issue was the sample was not representative of the population as only California teachers participated. The current study was predominantly female $(91.0 \%)$ and consisted of younger teachers when compared to the California average (U.S. Department of Education, 2019). Due to the small number of male participants, the study could not identify potential gender differences highlighted in some previous studies (McMahon, Martinez, et al., 2014). The current study also only included public schools in California due to limited resources. All these prevented a comparison of prevalence rate between states to identify potential patterns or factors causing more SBT to occur. Future studies should attempt to include charter and private schools, and schools from other states to better study how geographical and local political climate affects the rate of SBT.

Smith and Brain (2000) indicated the lack of support teachers experience was a possible factor creating the imbalance in power in the teacher-student relationship. Results from the current study showed teachers perceive a lack of awareness or support from the school, school districts, and parents. The majority of the teachers indicated the school, school districts, or parents were unsupportive or not aware of SBT. Past research has suggested SBT is a multi-systematic problem (McMachon, Martinez, et al., 2014). Therefore, future research should attempt to investigate the perspective of other key players in the ecology of the school and community.

Beyond the mental health concern for teachers, research has found, observing bullying to be unpleasant and have negative mental health concerns as well (Pepler \& Craig, 2000; Vartia, 2001). This indicates SBT not only reduced the work engagement of teachers; it has mental health impact on students observing SBT. The consequences are compounded, as students not involved with SBT suffer mental health consequences of observing bullying; they also lose out of teachers who become disengaged due to SBT. Future studies should consider studying SBT from the perspective of observing students 


\section{Conclusion}

The current study highlights SBT as a major concern within the school system. The rate of SBT in California appeared consistent with the national survey conducted several years ago. Despite the attention the APA Task Force attempted to bring to the phenomenon, nearly a decade later we are still observing little to no change for teachers struggling with SBT. Consistent with previous studies, the results suggest SBT does not only affect the teachers but also indirectly impacts the bully and other students not engaging in SBT. The effect of SBT has a direct and indirect consequence on the school, the school district, and the community at large as well.

\section{1 What to do about SBT?}

The majority of teachers highlighted students who are struggling academically as perpetrators of SBT. Research has found students use aggression to cope with frustration with struggles to adjust to academic or social demands (Thomas, Bierman, Thompson, \& Powers, 2008) and as a method to gain social hierarchy within the classroom (Garandeau, Ahn, \& Rodkin, 2011). This struggle can stem from a wide variety of issues like problems with attention (e.g., Becker \& McCloskey, 2002), social-cognitive deficits (Dodge, 2006), and undiagnosed learning disabilities or neurodevelopmental issues (O'Toole, Monks, \& Tsermentselli, 2017). Beyond student factors to an increase in SBT, school characteristics also contribute to an increase in aggressive behavior from students (Thomas et al., 2008). For example, lack of funding or supplies, high teacher-student ratio, lack of available earlyintervention programs, and negative classroom management techniques all have links to student's aggression at school (Perry, \& Weinstein, 1998). Home environment like poverty (Thomas \& Bierman, 2006) and parental aggression (McMahon, Martinez, et al., 2014) also shows strong links to student aggression. Thus, SBT can not be addressed but any one intervention program. It becomes clear; a multi-level program is required to tackle this problem.

\subsection{A systems approach to SBT.}

An ecological model was an ideal way to account for the benefits of a broader perspective without necessarily forgoing the intervention at individual levels (Holt-Lunstad, 2018). The social-ecological model of violence was a multilevel model of violence connecting a complex network of factors across different macro- and microsystems. As discussed earlier, SBT was influenced by a vast network of elements. Therefore, psychologists and other professionals needed to view SBT from a broader perspective rather than trying to solve SBT through individual intervention. This study has identified some factors within this model, and future studies should build on the current findings and continue identifying other protective and risk factors of SBT.

Based on the identified factors, we know some potentially effective interventions at each level. For students, it is vital to have school-wide programs to discourage the culture of aggression and bullying; this serves as an early prevention program. Findings from this study indicated students with academic struggles were most often the perpetrators of SBT. Plans need to be put in place to ensure students who need it have additional support, whether it is testing for learning disabilities or neurodevelopmental concerns, or other social welfare services. Teachers were also key players in this ecology. Teachers must have the awareness to report bullying at all levels and not turn a blind eye on less severe forms of bullying. At the same time, teachers should be provided with training to help identify potentially at-risk students and be familiarized with referral channels for students at a different level of needs. This then brings us to the responsibility of schools. Schools and districts should ensure effective intervention programs, including prevention, early intervention, and intensive intervention options. At the same time, schools should make sure information for these programs are easily accessible to teachers and parents. The school districts have to secure the services of crucial professionals for interventions at all levels. This includes school psychologists for testing, social workers to help connect students and their families to welfare services, or therapists to provide individual intervention for more severe cases.

Clinical psychologists receive training and are familiar with a systems approach when tackling problems. Familiarity with this approach helps the professional account for a broader range of factors, whether it is working with individual clients or acting as consultants to design and execute school or district-wide program. Clinical psychologists are also trained in research, collaboration, and consultation (Sullivan \& Long, 2010) and have a strong knowledge base for many of the protective and risk factors discussed above. This place clinical psychologists in a unique position to help tackle the SBT problem. Instead of having each program function as an individual unit within this complex network of systems, clinical psychologists can ensure the intervention programs work in collaboration with one another and get the best outcome for the entire ecology (i.e., student, 
teachers, schools, etc.).

\section{References}

Álvarez-García, D., García, T., \& Núñez, J. C. (2015). Predictors of school bullying perpetration in adolescence: A systematic review. Aggression and Violent Behavior, 23, 126-136.

Arseneault, L. (2017). The long - term impact of bullying victimization on mental health. World psychiatry, 16(1), 27-28.

Astor, R. A., Meyer, H. A., Benbenishty, R., Marachi, R., \& Rosemond, M. (2005). School safety interventions: Best practices and programs. Children \& Schools, 27(1), 17-32.

Becker, K. B., \& McCloskey, L. A. (2002). Attention and conduct problems in children exposed to family violence. American journal of orthopsychiatry, 72(1), 83-91.

Benefield, J. (2004, November). Teachers-the new targets of schoolyard bullies. In NZARE National Conference, Turning the Kaleidoscope, Westpac Stadium, Wellington (pp. 24- 26).

Benson, K. A. (1984). Comment on Crocker's" An Analysis of University Definitions of Sexual Harassment". Signs: Journal of Women in culture and Society, 9(3), 516-519.

Bester, S., Du Plessis, A., \& Treurnich, J. (2017). A secondary school teacher's experiences as a victim of learner cyberbullying. Africa Education Review, 14(3-4), 142-157.

Beyers, J. M., Loeber, R., Wikström, P. O. H., \& Stouthamer-Loeber, M. (2001). What predicts adolescent violence in better-off neighborhoods?. Journal of Abnormal Child Psychology, 29(5), 369-381.

Branford, J., Grahle, A., Heilinger, J. C., Kalde, D., Muth, M., Parisi, E. M., ... \& Wild, V. (2019). Cyberhate against academics. Responsibility for Refugee and Migrant Integration, edited by S. Karly Kehoe, Eva Alisic and Jan-Christoph Heilinger. Berlin/Boston: de Gruyter, 205-225.

Cain, J., Romanelli, F., \& Smith, K. M. (2012). Academic entitlement in pharmacy education. American Journal of Pharmaceutical Education, 76(10), 1-8; DOI: https://doi.org/10.5688/ajpe7610189

Chen, J. K., \& Astor, R. A. (2009). Students' reports of violence against teachers in Taiwanese schools. Journal of School Violence, 8(1), 2-17.

De Wet, C. (2010). Victims of educator-targeted bullying: a qualitative study. South African Journal of Education, 30(2), 189-201.

De Wet, C., \& Jacobs, L. (2006). Educator-targeted bullying: Fact or fallacy? Acta Criminologica, 19(2), 53-73.

Dhar, D., Jain, T., \& Jayachandran, S. (2019). Intergenerational Transmission of Gender Attitudes: Evidence from India. The Journal of Development Studies, 55(12), 2572-2592, DOI:10.1080/00220388.2018.1520214

Dodge, K. A. (2006). Translational science in action: Hostile attributional style and the development of aggressive behavior problems. Development and psychopathology, 18(3), 791-814.

Dzuka, J., \& Dalbert, C. (2007). Student violence against teachers: Teachers' well-being and the belief in a just world. European Psychologist, 12(4), 253-260. DOI:10.1027/1016-9040.12.4.253

Einarsen, S. (2000). Harassment and bullying at work: A review of the Scandinavian approach. Aggression and violent behavior, 5(4), 379-401.

Einarsen, S., Skogstad, A., Rørvik, E., Lande, Å. B., \& Nielsen, M. B. (2018). Climate for conflict management, exposure to workplace bullying and work engagement: a moderated mediation analysis. The International Journal of Human Resource Management, 29(3), 549-570.

Emmerová, I., \& Kohútová, J. (n.d.) Manifestations of Pupil Aggression towards Teachers in Elementary and Secondary Schools. Stanisław Juszczyk. 50(4), 17-25. DOI: 10.15804/tner.2017.50.4.01

Espelage, D. L., Holt, M. K., \& Henkel, R. R. (2003). Examination of peer-group contextual effects on aggression during early adolescence. Child Development, 74, 205-220.

Espelage, D. L., Low, S., Van Ryzin, M. J., \& Polanin, J. R. (2015). Clinical trial of second step middle school program: Impact on bullying, cyberbullying, homophobic teasing, and sexual harassment perpetration. School Psychology Review, 44(4), 464-479. 
Espelage, D., Anderman, E. M., Brown, V. E., Jones, A., Lane, K. L., McMahon, S. D., ... \& Reynolds, C. R. (2013). Understanding and preventing violence directed against teachers: Recommendations for a national research, practice, and policy agenda. American Psychologist, 68(2), 75-87.

Fahie, D., \& Devine, D. (2014). The impact of workplace bullying on primary school teachers and principals. Scandinavian Journal of Educational Research, 58(2), 235-252.

Garandeau, C. F., Ahn, H. J., \& Rodkin, P. C. (2011). The social status of aggressive students across contexts: The role of classroom status hierarchy, academic achievement, and grade. Developmental psychology, 47(6), 1699-1710.

Garrett, L. (2014). The Student Bullying of Teachers: An Exploration of the Nature of the Phenomenon and the Ways in which it is Experienced by Teachers. Aigne, 5, 19-40.

Glaser, R. (1984). Education and thinking: The role of knowledge. American Psychologist, 39(2), 93-104.

Gordon, J. A. (1997). Teachers of color speak to issues of respect and image. The Urban Review, 29(1), 41-66.

Harel-Fisch, Y., Walsh, S. D., Fogel-Grinvald, H., Amitai, G., Pickett, W., Molcho, M., ... \& Craig, W. (2011). Negative school perceptions and involvement in school bullying: A universal relationship across 40 countries. Journal of adolescence, 34(4), 639-652.

Hodgins, M., MacCurtain, S., \& Mannix-McNamara, P. (2014). Workplace bullying and incivility: a systematic review of interventions. International Journal of Workplace Health Management, 7(1), 54-72.

Holt-Lunstad, J. (2018). Why social relationships are important for physical health: A systems approach to understanding and modifying risk and protection. Annual review of psychology, 69, 437-458. https://doi.org/10.1146/annurev-psych-122216-011902

Huang, Y. S., \& Asghar, A. (2018). Science education reform in Confucian learning cultures: Teachers' perspectives on policy and practice in Taiwan. Cultural Studies of Science Education, 13(1), 101-131.

James, D. J., Lawlor, M., Courtney, P., Flynn, A., Henry, B., \& Murphy, N. (2008). Bullying behaviour in schools: what role do teachers play? Child Abuse Review, 17(3), 160-173. doi:10.1002/car.1025

Katz, J. (Presenter). (2012, November). Violence against women - it's a men's issue [TEDxFidiWomen Video] Retrieved from https://www.ted.com/talks/jackson_katz_violence against_women_it_s_a_men_s_issue

La Greca, A. M., \& Harrison, H. M. (2005). Adolescent peer relations, friendships and romantic relationships: Do they predict social anxiety and depression? Journal of Clinical Child and Adolescent Psychology, 34(1), 49-61. doi:10.1207/s15374424jccp3401_5

Lahelma, E., Palmu, T., \& Gordon, T. (2000). Intersecting power relations in teachers' experiences of being sexualized or harassed by students. Sexualities, 3(4), 463-481.

Leach, L. S., Poyser, C., \& Butterworth, P. (2016). Workplace bullying and the association with suicidal ideation/thoughts and behaviour: a systematic review. Occup Environ Med, 74(1), 72-79.

Lee, G. L., \& Manning, M. L. (2001). Treat Asian parents and families right. Multicultural Education, 9(1), 23-25.

Lewis, D. (2004). Bullying at work: The impact of shame among university and college lecturers. British Journal of Guidance \& Counselling, 32(3), 281-299.

May, A., \& Tenzek, K. E. (2018). Bullying in the academy: understanding the student bully and the targeted 'stupid, fat, mother fucker'professor. Teaching in Higher Education, 23(3), 275-290.

McCartney, N. (2018). Early Childhood Education Teachers' Job-Related Well-Being: Examining Protective Factors on Stress and Burnout (Doctoral dissertation).

McMahon, S. D., Martinez, A., Espelage, D., Rose, C., Reddy, L. A., Lane, K., ... \& Brown, V. (2014). Violence directed against teachers: Results from a national survey. Psychology in the Schools, 51(7), 753-766.

McVie, S. (2014). The impact of bullying perpetration and victimization on later violence and psychological distress: a study of resilience among a Scottish youth cohort. Journal of school violence, 13(1), 39-58.

Minor, M. A., Smith, G. S., \& Brashen, H. (2013). Cyberbullying in higher education. Journal of Educational Research and Practice, 3(1), 15-29.

Mooij, T. (2011). Differences in pupil characteristics and motives in being a victim, perpetrator and witness of violence in secondary education. Research Papers in Education, 26(1), 105-128.

O'connell, P. A. U. L., Pepler, D., \& Craig, W. (1999). Peer involvement in bullying: Insights and 
challenges for intervention. Journal of adolescence, 22(4), 437-452.

Olweus, D. (1991). Bully/victim problems among school children: Basic facts and effects of a school based intervention program. In I. Rubin \& D. Pepler (Eds.), The Development and Treatment of Childhood Aggression (pp. 411-447). Hillsdale, NJ: Erlbaum.

O'Toole, S. E., Monks, C. P., \& Tsermentseli, S. (2017). Executive function and theory of mind as predictors of aggressive and prosocial behavior and peer acceptance in early childhood. Social Development, 26(4), 907-920.

Özkiliç, R. (2012). Bullying toward Teachers: An Example from Turkey. Eurasian Journal of Educational Research, $47,95-112$.

Pepler, D. J., \& Craig, W. (2000). Making a difference in bullying. LaMarsh report, 59.

Perry, K. E., \& Weinstein, R. S. (1998). The social context of early schooling and children's school adjustment. Educational psychologist, 33(4), 177-194.

Pervin, K., \& Turner, A. (1998). A study of bullying of teachers by pupils in an inner London school. Pastoral Care in Education: An International Journal of Personal, Social and Emotional Development, 16(4), 4-10. doi:10.1111/1468-0122.00104

Podolsky, A., Kini, T., Bishop, J., \& Darling-Hammond, L. (2016). Solving the teacher shortage: How to attract and retain excellent educators. Palo Alto, CA: Learning Policy Institute. Retrieved from https://learningpolicyinstitute.org/product/solving-teacher-shortage.

$\begin{array}{lllll}\text { Point2Homes } & \text { (n.d.) } & \text { California } & \text { demographics. } & \text { Retrieved }\end{array}$ https://www.point2homes.com/US/Neighborhood/CA-Demographics.html

Robinson, K. (2000). " Great Tits, Miss!" The silencing of male students' sexual harassment of female teachers in secondary schools: A focus on gendered authority. Discourse: studies in the cultural politics of education, 21(1), 75-90

Santos, A., \& Tin, J. J. (2018). The nature, extent and impact of educator targeted bullying on schoolteachers in West Malaysia. British Journal of Guidance \& Counselling, 46, 543-556.

Smith, A. (2007). Cyber bullying affecting 17\% of teachers, poll finds. Education Guardian. Retrieved from http://www.guardian.co.uk/education/2007/jan/19/schools.uk

Smith, P. K., \& Brain, P. (2000). Bullying in schools: Lessons from two decades of research. Aggressive Behavior: Official Journal of the International Society for Research on Aggression, 26(1), 1-9.

Smith, P. K., \& Thompson, D. (2017). Practical approaches to bullying. Lond, England: Routledge.

Smith, T. M., \& Ingersoll, R. M. (2004). What are the effects of induction and mentoring on beginning teacher turnover?. American educational research journal, 41(3), 681-714.

Smith, V. G., Mack, F. R., \& Akyea, S. G. (2004). African-American male honor students' views of teaching as a career choice. Teacher Education Quarterly, 31(2), 75-88.

Sullivan, A. L., \& Long, L. (2010). Examining the changing landscape of school psychologypractice: A survey of school - based practitioners regarding Response to Intervention. Psychology in the Schools, 47(10), 1059-1070.

Tao, Y., Oliver, M., \& Venville, G. (2013). A comparison of approaches to the teaching and learning of science in Chinese and Australian elementary classrooms: Cultural and socioeconomic complexities. Journal of Research in Science Teaching, 50(1), 33-61.

Terry, A. A. (1998). Teachers as targets of bullying by their pupils: A study to investigate incidence. British Journal of Educational Psychology, 68(2), 255-268.

Thomas, D. E., Bierman, K. L., \& Conduct Problems Prevention Research Group. (2006). The impact of classroom aggression on the development of aggressive behavior problems in children. Development and psychopathology, 18(2), 471-487.

Thomas, D. E., Bierman, K. L., Thompson, C., \& Powers, C. J. (2008). Double jeopardy: Child and school characteristics that predict aggressive-disruptive behavior in first grade. School Psychology Review, 37(4), 516-532.

U.S. Department of Education, National Center for Education Statistics. (2019). Digest of education statistics, 
2017 (NCES 2018-070). Washington, DC: National Center for Education Statistics.

Vartia, M. A. (2001). Consequences of workplace bullying with respect to the well-being of its targets and the observers of bullying. Scandinavian journal of work, environment \& health, 63-69.

Wilson, C. M., Douglas, K. S., \& Lyon, D. R. (2011). Violence against teachers: Prevalence and consequences. Journal of Interpersonal Violence, 26, 2353-2371.

\section{About the author:}

Jia Jian Tin M.S. is a doctoral candidate in a clinical psychology Ph.D. program at the California School of Professional Psychology (CSPP), Fresno campus. He is currently on his full-time APA internship at State Center Community College District providing individual and group therapy to students at the community college district. Mr. Tin received his M.S. in applies criminology from California School of Forensic Studies, Fresno in 2016 and his M.A. in clinical psychology from CSPP, Fresno in 2018. He projected to graduate with a Ph.D. in clinical psychology from CSPP Fresno in 2021. 